\title{
DIVULGACIÓN DE LAS INVESTIGACIONES EN ATAPUERCA (BURGOS)
}

\author{
POPULARISING THE RESEARCH AT ATAPUERCA (BURGOS)
}

\author{
M. ${ }^{a}$ ELENA NICOLÁS CHECA (*) \\ BELÉN MÁRQUEZ MORA (*) \\ JESÚS RODRÍGUEZ MÉNDEZ (*)
}

\section{RESUMEN}

La exposición “Atapuerca: nuestros antecesores" en el Museo Nacional de Ciencias Naturales (MNCN) pone al alcance del gran público los resultados de 20 años de investigación. Para ello se han utilizado los recursos expositivos más innovadores, incluyendo las últimas tecnologías audiovisuales, maquetas, dioramas e interactivos no informáti$\cos$, al tiempo que se han expuesto piezas originales nunca antes mostradas al gran público. Los talleres que se han diseñado paralelamente a la exposición suponen la participación activa del visitante y permiten conjugar aprendizaje y diversión.

\begin{abstract}
The "Atapuerca: our ancestors" exhibition at the $M N C N$ shows the results of 20 years of scientific research. Innovative exhibition resources have been applied, including the newest audio-visual technologies, models, dioramas, and non computer-based interactive elements. At the same time, fossils never exhibited before are shown. Other activities like workshops, allowing active participation of visitors, combine active learning with enjoyment.
\end{abstract}

Palabras clave: Atapuerca. Burgos. Evolución humana. Divulgación. Taller. Pleistoceno Medio. Museo Nacional de Ciencias Naturales (C.S.I.C.).

Key words: Atapuerca. Burgos. Human Evolution. Popularising. Workshop. Middle Pleistocene. Museo Nacional de Ciencias Naturales (C.S.I.C.).

(*) Dpto. de Paleobiología. Museo Nacional de Ciencias Naturales. C.S.I.C. José Gutiérrez Abascal, 2. 28006 Madrid. Correo electrónico (EN) mcnen553@mncn.csic.es (BM) bmm@mncn. csic.es (JR)jrm@mncn.csic.es Belén Márquez es becaria predoctoral de la Fundación Duques de Soria y Jesús Rodríguez es becario postdoctoral de la Comunidad de Madrid.

El artículo fue remitido en su versión final el 7-IX-00.

\section{INTRODUCCIÓN Y OBJETIVOS}

En las entrañas de la Sierra de Atapuerca (Burgos) (Fig. 1) se ha desarrollado desde el principio del Mioceno un complejo kárstico en las calizas cretácicas (Zazo et alii, 1983). Sus cuevas y galerías subterráneas albergan las evidencias que nos permiten acceder al estudio de la historia de los seres humanos y de los ambientes en los que vivieron durante el último millón de años.

Desde que EmilianoAguirre, Profesor de Investigación jubilado y actualmente doctor vinculado al MNCN y miembro de la RealAcademia de Ciencias Exactas, Físicas y Naturales, se hizo cargo de los primeros restos humanos aparecidos, ha transcurrido un cuarto de siglo. El esfuerzo investigador ha estado centrado en el estudio de la evolución de la humanidad europea y el contexto ecológico en el que dichos cambios tienen lugar. A lo largo de estos años se ha ido forjando un grupo de científicos responsable de la investigación en distintas disciplinas, que en 1997 fue galardonado con el Premio Príncipe de Asturias de Investigación Científica y Técnica (Comité de Redacción, 1997) (1). En diciembre de 2000 la Sierra deAtapuerca ha sido declarada Patrimonio de la Humanidad por la UNESCO.

Las publicaciones científicas sobre los yacimientos y los hallazgos realizados son muy abundantes y se han ido sucediendo con mucha continuidad. Tampoco se ha detenido la divulgación de los descubrimientos y de las conclusiones más importantes obtenidas a partir de ellos: a través de confe-

(1) htpp://www.mncn.csic.es/atapuerca/last atapuerca/inicio. htm

http://www.romani.iua.urv.es/

http://www.atapuerca.geo.ucm.es/

Páginas del equipo de Atapuerca en el Museo Nacional de Ciencias Naturales (C.S.I.C., Madrid), Universitat Rovira iVirgili (Tarragona) y Universidad Complutense (Madrid), respectivamente. 


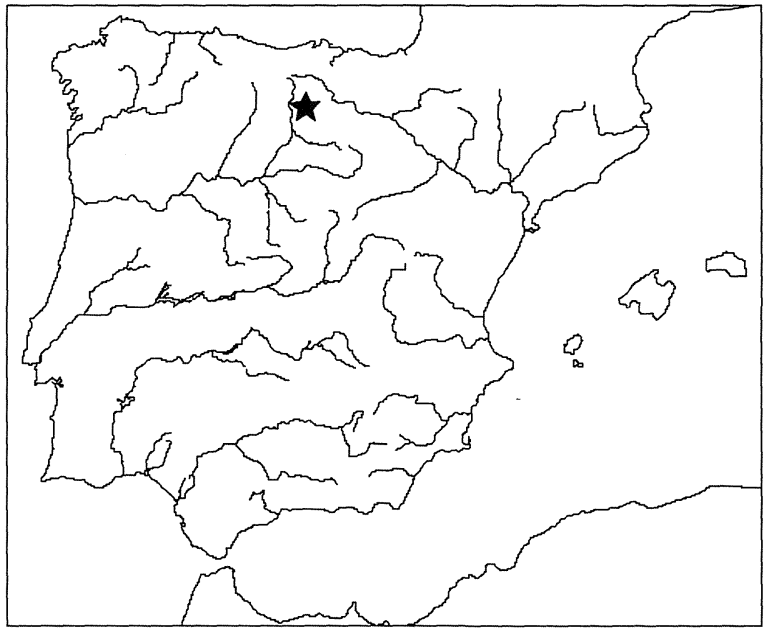

Fig. 1. Situación de la Sierra de Atapuerca (Burgos) en la Península Ibérica.

rencias o de las Jornadas de Puertas Abiertas durante las campañas de excavación de los yacimientos, los castellano-leoneses de a pie han ido conociendo, al día, la actualidad deAtapuerca. Pero además, en los últimos tres años se ha redoblado esfuerzo y empeño por dar a conocer al gran público los resultados científicos del equipo investigador de Atapuerca. Conferencias, actos de presentación, exposiciones fotográficas, vídeos y libros de divulgación, han protagonizado la oferta didáctica y educativa del proyecto de Atapuerca (p.e. Arsuaga y Martínez, 1998; Arsuaga, 1999; Cervera et alii, 1998; Carbonell y Sala, 2000). Todo ello ha influido sin duda en la reciente propuesta de Atapuerca como Patrimonio de la Humanidad.

En este contexto se enmarcaba el episodio más intenso en el ámbito divulgativo de los contenidos científicos deAtapuerca: la exposición "Atapuerca: nuestros antecesores" del Museo Nacional de Ciencias Naturales de Madrid (C.S.I.C.) y la publicación de un catálogo con la misma temática de 221 páginas y más de 300 ilustraciones (Bermúdez de Castro et alii, 1999).

Dicha muestra cosechaba y compilaba los esfuerzos de años de investigaciones sobre la sierra. En el momento de la gestación de dicho proyecto, la participación acumulada del equipo de Atapuerca, en recursos humanos esporádicos o fijos, estaba integrada ya por centenares de estudiantes cualificados, becarios especialistas e investigadores que trabajaban y colaboraban de forma más o menos intensa y continuada en las excavaciones de los rellenos, la realización de las memorias y las investigaciones.
Esta exposición llegó en un momento excelente. La relevancia de los últimos descubrimientos, por la cantidad y la calidad de los restos, había producido un reavivamiento del interés de la sociedad por las cuestiones relacionadas con la evolución de los trabajos en los yacimientos, así como por la evolución de los propios ecosistemas y formas de vida humana de la sierra. Los yacimientos y sus descubrimientos han sido difundidos con profusión, generando con ello expectativas de interés por los nuevos hallazgos y los resultados obtenidos a partir de su estudio.

A lo largo de los años se habían sucedido experiencias negativas (salvo honrosas excepciones) en la transmisión de información desde los medios de comunicación de masas hasta la sociedad, a quien llegaban informaciones de dudosa naturaleza y mensajes pseudocientíficos ya con una importante acumulación de errores en su divulgación.

También es cierto el hecho de que las rigurosas revistas científicas nacionales o extranjeras son raramente accesibles para el público, tanto físicamente como por su forma de comunicar resultados. Además, la actualización científica no llega a los libros de texto con la celeridad deseable y no siempre resulta fácil acortar estas distancias. Entre los objetivos planteados entonces, estaba el de comunicar y divulgar de forma amena, pero con el máximo rigor, los resultados de un proyecto científico de renombre y reconocimiento internacional. Por tanto, resultaba lógico y necesario decidirse a realizar un macroproyecto que tradujera de forma adecuada, y al espectro más amplio posible de la sociedad, los resultados científicos obtenidos a lo largo de todo este tiempo.

Así, el Equipo Investigador de Atapuerca acogió con entusiasmo la posibilidad que le brindaba el Museo Nacional de Ciencias Naturales de montar una gran exposición sobre Atapuerca. El imprescindible apoyo económico al proyecto vino a través de la Fundación del Patrimonio Histórico de Castilla y León, compuesta por la Junta de Castilla y León, Caja España, Caja Duero, Caja de Ahorros Municipal de Burgos, Caja de Ahorros del Círculo Católico de Burgos, Caja de Ahorros de Segovia y Caja de Ahorros de Ávila. El proyecto expositivo se benefició también de la colaboración de la Sociedad de Amigos del Museo Nacional de Ciencias Naturales.

Además de la difusión de los resultados de mayor alcance obtenidos a partir de las investigaciones se ha realizado el esfuerzo de explicar los pro- 
cedimientos por los cuales se pueden llegar a esas conclusiones, las formas de investigar que cada miembro del equipo multidisciplinar desarrolla, con las técnicas y mecanismos de que se sirve y que utiliza. No se ha pretendido entonces realizar una mera exhibición del abundantísimo material recuperado en estos yacimientos. Los fósiles y las piezas de industria lítica que se mostraron no eran numerosos, pero sí selectos, jugando un papel específico y determinante a la hora de ilustrar el discurso planteado. Por la misma razón, la explicación del trabajo científico ha sido el otro hilo conductor de la exposición. Por último, como objetivo subyacente a toda la comunicación divulgativa realizada, se ha pretendido promover el respeto y la conservación del medio, de su diversidad y el patrimonio arqueopaleontológico.

Estos objetivos pudieron materializarse gracias a que desde las primeras fases del diseño de la exposición se constituyó un equipo formado por especialistas del Departamento de Exposiciones y Programas públicos del MNCN (con Luis Alcalá a la cabeza, como vicedirector de Exposiciones) y por miembros del Equipo Investigador de Atapuerca, bajo la dirección de José M. ${ }^{a}$ Bermúdez de Castro, comisario científico de la exposición (Fig. 2). Ambos equipos trabajaron al unísono para compatibilizar rigor científico, amenidad y claridad.

\section{CONTENIDOS CIENTÍFICOS EN LA EXPOSICIÓN EN EL MUSEO DE CIENCIAS NATURALES DE MADRID}

El proyecto de divulgación científica se articuló según un orden muy pensado y establecido de contenidos. Las ideas que se intentaron transmitir conservaban todo su rigor científico, pero a la vez tenían que llegar de forma eficiente, concisa, clara, correcta y amena a un rango lo más amplio posible de público, segmentado según sus diferentes grados de formación. La exposición estaba planteada para que pudieran realizarse distintos niveles de lectura de la misma, y por tanto, ofrecer la posibilidad de realizar este aprovechamiento diferencial de conocimientos.

\section{Organización espacial de los contenidos}

A lo largo de la muestra, los contenidos expuestos se dividieron en tres grupos de conocimiento

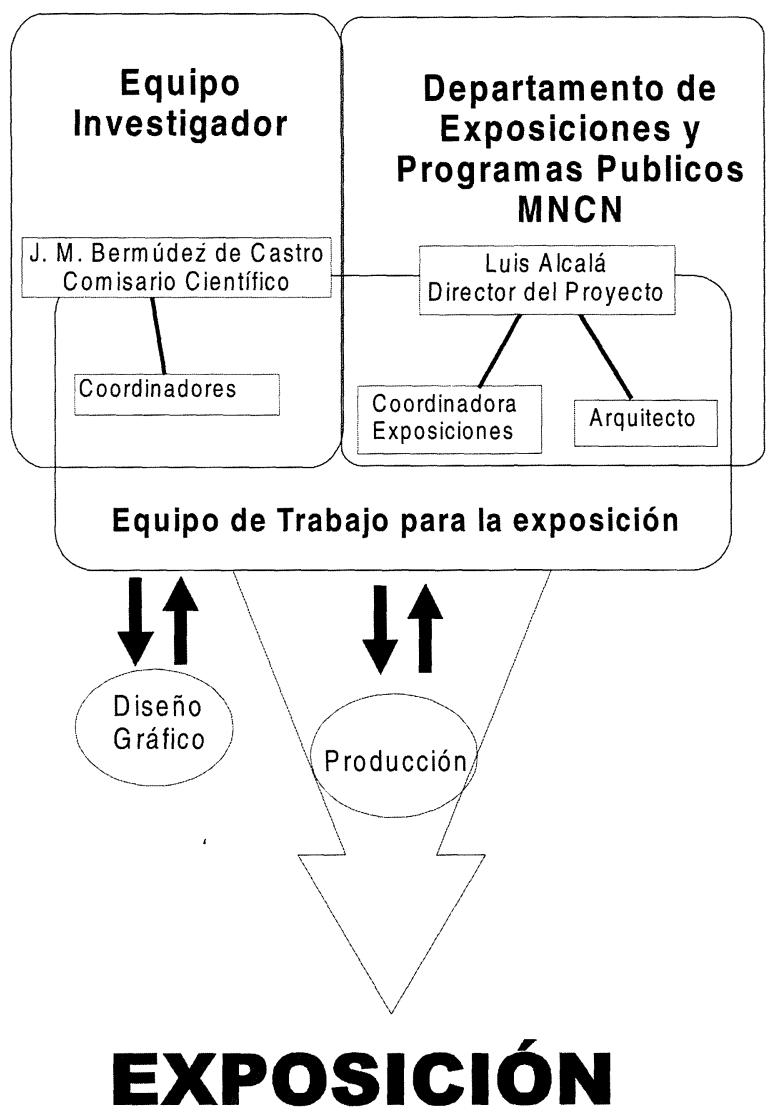

Fig. 2. Organigrama detallando la composición del equipo que intervino en el diseño y montaje de la exposición "Atapuerca: nuestros antecesores".

identificados por zonas (Fig. 3). La primera de ellas contenía la información relacionada con los yacimientos de la Trinchera del Ferrocarril y con la especie Homo antecessor, a la que pertenecen los primeros grupos humanos que se aventuraron a salir del continente africano e iniciaron el poblamiento del actual continente europeo. En los distintos bloques se han podido adquirir conocimientos sobre el descubrimiento, la excavación y la restauración de los restos deHomo antecessor, sus relaciones de semejanza morfológica y de parentesco con nuestra propia especie, su comportamiento cultural y subsistencial y la investigación de sus modos de vida y su devenir evolutivo. Se abordaban también aquí la paleoecología, el comportamiento nutricional de los grupos humanos que vivieron en la sierra y los cambios culturales y en la industria lítica que tuvieron lugar durante el Pleistoceno inferior y medio.

La segunda parte de la exposición aproximaba al visitante al conocimiento de los grupos humanos de la especie $H$. heidelbergensis y del yacimiento en 


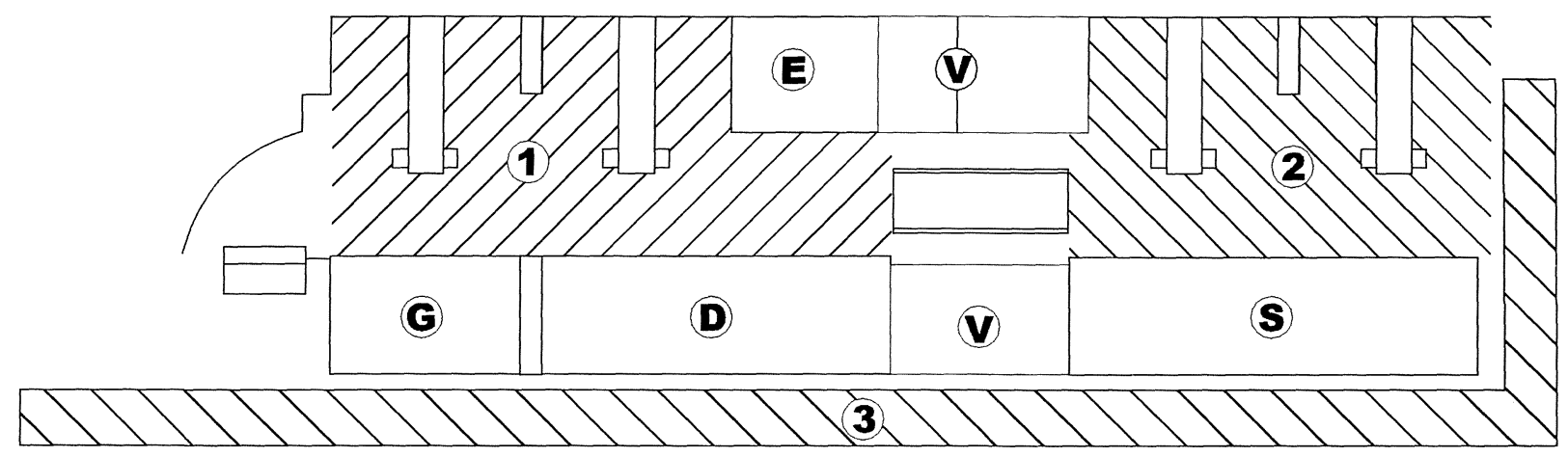

Fig. 3. Esquema de la exposición "Atapuerca: nuestros antecesores". 1. Primera Parte: Homo antecessor y los yacimientos de la Trinchera del Ferrocarril. 2. Segunda parte: Homo heidelbergensis y los neandertales. 3. Tercera parte: ¿Qué nos hizo humanos? E. Escena de Homo heidelbergensis. G. Reproducción parcial del yacimiento de Galería a escala 1:1. D. Reproducción parcial del yacimiento de Gran Dolina a escala 1:1. S. Reproducción de la Sima de los Huesos a escala 1:1. V. "Mediateca".

el que se han recuperado la gran mayoría de los restos de esta especie que existen en el mundo: la Sima de los Huesos.

Entre el primer y segundo ámbito estaba situada una zona con recursos audiovisuales. Formaban parte de ella distintos elementos que constituyen un componente más novedoso a la hora de presentar los contenidos: el teatro virtual, la mediateca, con distintos interactivos, los cascos de audición y la sala de proyección de documentales.

La tercera y última parte se separó espacialmente del resto, no sin cierta intencionalidad. En ella se visitaba de forma resumida nuestro conocimiento actual acerca de cómo nos hemos convertido en humanos y qué es lo que nos separa de nuestros ancestros remotos. Estaba destinada a un público más especializado, con interés mayor o más específico en temas de evolución humana.

\subsection{Representaciones tridimensionales. La dimen- sión espacial}

La utilización de recursos tridimensionales, con diferentes escalas, ha jugado un papel fundamental a lo largo de toda la exposición. Se ha prestado gran atención al empleo de los mismos por su capacidad para transmitir una gran cantidad de información objetiva y fácilmente asimilable por todos, y con la idea de situar dimensional y espacialmente a los visitantes. Con este fin, la exposición comenzaba ante una maqueta a escala 1: 300 de la Sierra de Atapuerca y la Trinchera del Ferrocarril. Los visitantes podían instruirse acerca del contexto geográfico y conocer las características fisiográficas de la Sierra de Atapuerca. En la maqueta, el visitante podía apreciar las relaciones de distancia entre los diferentes yacimientos de la Trinchera y también entre éstos y la entrada a Cueva Mayor desde donde se accede al yacimiento de la Sima de los Huesos.

A espaldas de esta maqueta se disponía otra, construida a escala 1: 50, en la que se reproducían los yacimientos de Galería y Gran Dolina (Lám. I). En ella se ha intentado simular el tipo de vegetación (encinas y quejigos) que puebla la sierra. Se visualiza muy bien la diferencia entre las cuevas, que tienen paredes de coloraciones grises o blancuzcas y están formadas a partir de la disolución de la caliza, y los rellenos cársticos acumulados durante muchos miles de años, que presentan coloraciones rojizas. La escala 1: 50 combinada con unas técnicas que permiten alcanzar un acabado hiperrealista hace posible transmitir una gran cantidad de información con un solo elemento expositivo de dimensiones relativamente reducidas. Esta escala resultaba ideal para comenzar a captar la atención del público, y además reproducir con mucho detalle varios aspectos relacionados con la infraestructura de las excavaciones así como las herramientas y métodos de excavación arqueológicos.

Los yacimientos de Gran Dolina y Galería han necesitado grandes andamiajes para protegerlos de la erosión y conservar el registro en su contexto estratigráfico preciso, algo estrictamente necesario en cualquier proyecto de excavación sistemática. En la maqueta se observan los sistemas de protección y acceso a los yacimientos y las dos excavaciones que se venían desarrollando hasta el momento en Gran Dolina: la primera en una extensión de unos

T. P., 57, n. $^{\circ} 2,2000$ 


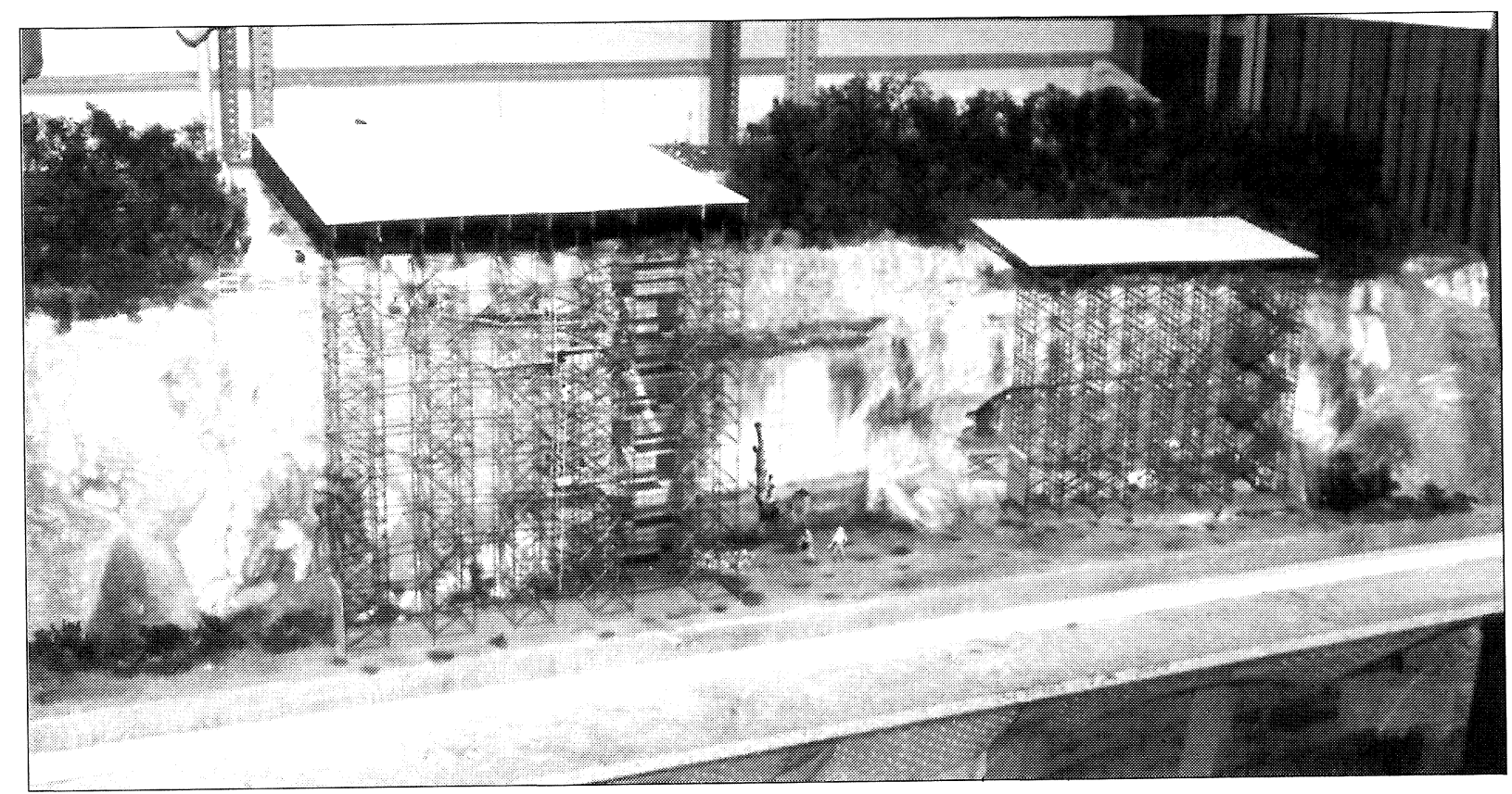

Lám. I. Vista de la maqueta a escala 1:50 de los yacimientos de Gran Dolina y Galería (Sierra de Atapuerca). Exposición "Atapuerca: nuestros antecesores".

$100 \mathrm{~m}^{2}$, actualmente en el nivel TD10; la segunda, una prospección arqueológica llamada Dolina Sondeo, de aproximadamente $6 \mathrm{~m}^{2}$ de planta en la parte derecha, y que ha llegado al suelo de la cueva en la campaña de excavación de 1999.

La función que cumplían estas maquetas se complementó con las reproducciones escenográficas parciales a escala 1: 1, de gran fidelidad, de Gran Dolina y Galería además de una reproducción íntegra del yacimiento de la Sima de los Huesos. Las tres reproducciones aproximaban al visitante a la gran potencia estratigráfica de los yacimientos, y al interés científico de los rellenos fosilíferos. Las excavaciones y las investigaciones todavía consumirán en el futuro enorme esfuerzo de trabajo y recursos humanos. Todas las representaciones persiguieron la consecución de un acabado extraordinariamente realista. Durante docenas de horas se estudió minuciosamente un sinfín de detalles que se tuvieron en cuenta en la realización de las reconstrucciones a gran escala de los yacimientos de Galería, Gran Dolina y La Sima de los Huesos.

En la reproducción parcial de Galería se representó la zona que corresponde a la Covacha de los Zarpazos. Aquí se ilustraba el trabajo de los geólogos en la estratigrafía, el diseño de la cuadrícula aérea que segmenta y permite identificar con precisión el espacio a excavar, y las piezas que se encuentren en ese espacio. Se apreciaban los testigos que quedan por excavar y el aspecto que tiene el yacimiento, que pretende musealizarse en el futuro.

Gran Dolina tiene 11 niveles estratigráficos y casi 20 m. de altura (Parés y Pérez González, 1995). En la reproducción parcial de la Gran Dolina se representaron los niveles superiores, donde se observaban las herramientas e infraestructuras reales utilizadas durante las excavaciones, como andamiajes, sistemas de excavación y de recogida de datos, y a tamaño real, el sondeo estratigráfico. En él, los visitantes se acercaban al momento y al escenario real en el que se produjeron los descubrimientos de los restos humanos europeos más antiguos conocidos hasta el momento, y de más de 780000 años de antigüedad (Parés y Pérez González, 1995).

Gracias a la reproducción de la Sima de los Huesos a escala 1: 1, el visitante entendía las dificultosas condiciones de acceso y excavación en el interior de una cueva. Este yacimiento, con una cronología de entre 250000 y 300000 años de antigüedad (Bischoff et alii, 1997) se encuentra en una cavidad ciega, a la que se llega tras un recorrido sinuoso, por galerías subterráneas, estrechamientos y gateras dentro del complejo Cueva Mayor- Cueva del Silo. 
1.2. La primera parte: paleoecología, industria lítica, modos de vida y la nueva especie Homo antecessor

\subsubsection{Las claves de Atapuerca}

La antigüedad de los fósiles recuperados enAtapuerca constituye un aspecto de sumo interés para todos los públicos. Los distintos métodos de datación permiten conocer la antigüedad del registro. Un error frecuente y muy extendido suele ser el pensar que el C14 es el método por excelencia, y una gran parte de los visitantes destierra esa idea después de entender el rango cronológico que permite datar cada método y qué técnicas se han empleado en Atapuerca (radiométricas, paleomagnetismo y bioestratigrafía). Todos estos conceptos han sido transmitidos a través de paneles mediante textos sencillos apoyados en gráficos y esquemas.

En este primer ámbito se insistía en que el descubrimiento de fósiles humanos en Atapuerca es doble, puesto que son dos especies humanas cronológica y anatómicamente diferentes las aparecidas en los yacimientos.

\subsubsection{Los homínidos de Gran Dolina y las reconstrucciones anatómicas}

Homo antecessor es una especie nueva, descrita a partir de los restos aparecidos en el "Estrato Aurora" del nivelTD6, dentro del sondeo estratigráfico de Gran Dolina (Bermúdez de Castro et alii, 1997; Carbonell et alii, 1995). El primer resto fue hallado, durante la campaña de excavación, por la arqueóloga Aurora Martín el 8 de julio de 1994. La importancia de estos restos es aún más patente al haber sido recuperados junto a parte de su contexto biológico (faunas acompañantes) y cultural (herramientas que fabricaron y utilizaron). El hecho de que hayan fosilizado restos maxilares y mandibulares permite además conocer, por el estado de desarrollo de las piezas dentarias, las edades de muerte de los distintos individuos, e incluso si sus dientes tenían procesos de crecimiento y erupción similares a los nuestros. Con ello sabemos que casi un centenar de restos humanos recuperados pertenecen al menos a 6 individuos distintos: dos niños, dos adolescentes y dos adultos jóvenes. En una vitrina se mostraban restos dentarios de tres de estos individuos de edades diferentes, con el fin de que el visitante pudiera comparar las diferencias entre ellos.
La nueva especie (antecessor $=$ explorador, pionero) se sitúa en la base de la dicotomía genealógica entre neandertales (Homo neanderthalensis) y Homo sapiens, como resultado de la combinación única de rasgos anatómicos de los dientes, la mandíbula y el cráneo de estos homínidos (Carbonellet alii, 1995). En contraste con los rasgos modernos de la cara, casi indistinguible de la de los humanos modernos, los dientes presentan una morfología muy primitiva que les enlaza con la línea evolutiva africana. Dos vitrinas, en las que se mostraban restos de $H$. antecessor, neandertales y hombres modernos, permitían comparar estas semejanzas y diferencias.

El estudio tafonómico es el objeto de otra disciplina relacionada con la Paleontología. La Tafonomía estudia las alteraciones que sufrieron los huesos desde la muerte del animal, durante su enterramiento o fosilización. EnTD6, tanto los restos de fauna como los humanos presentan en su superficie marcas de corte para el descuartizamiento y el aprovechamiento de la carne, y las diáfisis de los huesos largos presentan evidencias de haber sido fracturadas intencionadamente para extraer la médula. Con el fin de mostrar la semejanza entre el tratamiento dado a los restos humanos y el deparado a la fauna, se exhibían en una misma vitrina 3 restos humanos y 3 restos de un bóvido con fracturaciones antrópicas y marcas de corte. Este comportamiento caníbal es probablemente de tipo gastronómico, ya que los datos existentes apuntan a que existía intencionalidad nutricional, quedando excluida la idea de que se trate de cualquier posible ritual.

Las reconstrucciones de los rostros de los individuos y de la escena de canibalismo acercan en el tiempo a las dos especies: la observadora y la observada (Lám. II). El rigor científico y la belleza de los resultados son siempre la nota predominante en las reconstrucciones realizadas por el dibujante científico.

La restauración y el moldeo de los fósiles humanos permite introducir al gran público el trabajo que realizan el Departamento de Restauración del Museo Nacional de Ciencias Naturales de Madrid, el equipo de restauración del Laboratorio de Arqueología de la Universitat Rovira i Virgili de Tarragona y del Departamento de Paleontología de la Facultad de Ciencias Geológicas (Universidad Complutense de Madrid). Como se ha mostrado en fotos y reproducciones en una de las vitrinas de la exposición, el estado de algunos restos exige un considerable esfuerzo para conseguir eliminar las

T. P., 57, n. $^{\circ} 2,2000$ 


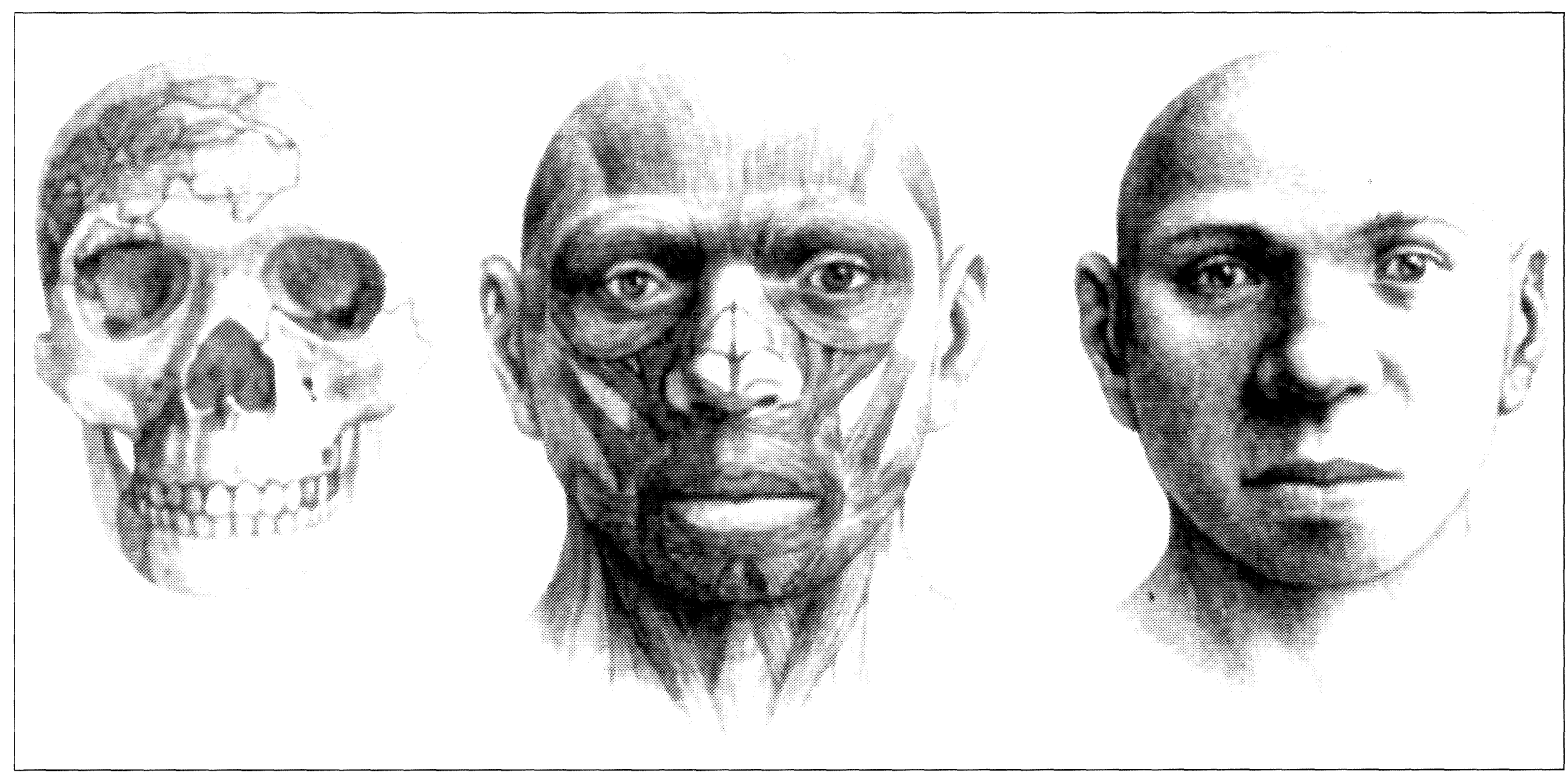

Lám. II. Secuencia de reconstrucción del aspecto en vida de Homo antecessor a partir del maxilar y el frontal de TD6 (Gran Dolina, Sierra de Atapuerca) (reconstrucción M.Antón).

carbonataciones que presentan, y realizar las réplicas de alta resolución.

\subsubsection{Los fósiles en su ambiente}

La Paleoecología estudia las relaciones entre sí y con su ambiente de los seres que habitaban en el pasado. Al gran público siempre le ha llamado la atención el estudio de la vida y de las relaciones entre los distintos organismos vivientes, de forma que un objetivo era conseguir que a la cultura popular llegara con idéntico interés y con la misma fascinación el estudio de los cambios que se han ido sucediendo a lo largo del tiempo en las faunas y en el paisaje vegetal. El estudio de estos cambios es el objetivo principal de la ciencia paleontológica. Algunas especies evolucionan cambiando solamente algunas de sus estructuras, y dan lugar a otras distintas. Otras se extinguen sin dejar descendencia o migran hacia otros lugares de climas favorables y son reemplazadas por otras completamente diferentes.

El paso previo a un estudio paleoecológico es tener un buen conocimiento de la anatomía y poder identificar correctamente las especies con las que se va a trabajar. Para la fauna, los paleontólogos taxónomos cuentan con la ayuda de publicaciones científicas y de colecciones de referencia o de com- paración de esqueletos actuales que existen en los museos.

Esta idea se ha intentado transmitir a través de la exhibición de varios restos fósiles de un lince y un castor junto a sendos esqueletos montados de dos animales actuales. El polen producido por las plantas que crecen en el entorno del yacimiento también pasa a formar parte de los sedimentos, con el viento o gracias a las egagrópilas que arrojan las rapaces que nidifican cerca de las cuevas. El polen es también un excelente indicador de la planta a la que perteneció. Al visitante le llama la atención cómo algunos fósiles hallados en los yacimientos aportan una gran cantidad de información, a pesar de sus reducidísimas dimensiones. El polen no sólo proporciona datos acerca de las plantas que existieron en cada momento, sino de los cambios climáticos que se habían ido sucediendo.

Pero no es menos interesante conocer cómo y después de qué procesos han llegado los fósiles hasta el lugar en el que los encontramos, desde que se produce la comunidad muerta hasta que ésta se constituye en la comunidad fosilizada que arqueólogos y paleontólogos desentierran, siempre en sentido inverso al orden de su formación. Con la información proporcionada por la fauna y la vegetación se puede tener una idea muy completa acerca de cómo se sucedieron los cambios paisajísticos a lo largo del tiempo, y en parte también de cómo 


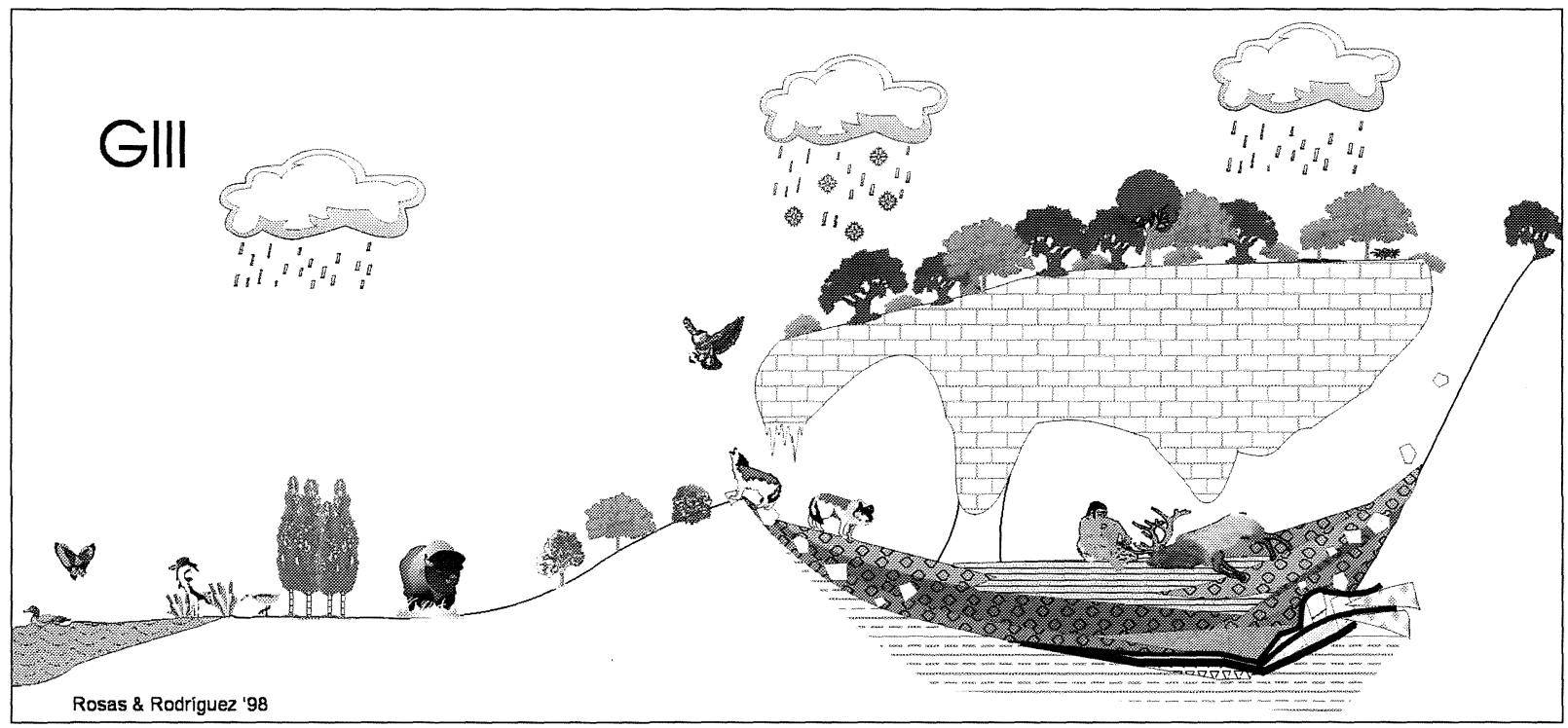

Fig. 4. Reconstrucción esquemática del paisaje, ocupación y relleno de la Unidad GIII del yacimiento de Galería (Sierra de Atapuerca). Tomado de Rosas et alii (1999).

se fueron rellenando y poblando las cuevas en cada momento. Estas ideas fueron recogidas en una secuencia de dibujos esquemáticos y cuadros al óleo que reproducían la evolución en el tiempo del paisaje de Atapuerca (Fig. 4).

\subsubsection{La industria lítica}

Entre las materias primas más utilizadas para la fabricación de útiles líticos destacan el sílex y la cuarcita, aunque otros materiales empleados en menor proporción incluyen la arenisca, el cuarzo, la pizarra o la caliza. Ejemplos de todas estas rocas, procedentes de los mismos afloramientos explotados por los homínidos, han sido expuestos en este ámbito. El acceso a las materias primas era sencillo, y podían obtenerlas del entorno próximo a la Sierra (2).

A lo largo de un millón de años se fueron produciendo cambios culturales que quedaron reflejados en los distintos tipos de herramientas fabricadas, que progresivamente tendieron hacia una mayor complejidad y especialización. Esta evolución se

(2) García-Antón, D. (1997): El origen geológico y de la alteración del sílex arqueológico del Complejo Galería subnivel GIIa. (Sierra de Atapuerca, Burgos). Tesis de Licenciatura. Inédita. Facultat de Lletres. Universitat Rovira i Virgili. Tarragona. Mallol, C. (1997): Estudio de la selección de materias primas líticas en los niveles TD6 y TD10 del yacimiento de Gran Dolina (Sierra de Atapuerca, Burgos). Tesis de Licenciatura. Inédita. Facultat de Lletres. Universitat Rovira i Virgili. Tarragona. presentaba en tres paneles distintos en los que se exhibían algunas piezas representativas de cada Modo Técnico. Al contar con un complejo de yacimientos de gran potencia estratigráfica y amplio rango cronológico, en Atapuerca se ha podido estudiar la evolución de las técnicas de talla y los distintos modos culturales.

Durante las visitas guiadas se mostraban algunas réplicas de distintos útiles a los visitantes, quienes fijándose y tocando las piezas podían trabajar sobre las categorías establecidas recién aprendidas, para así fijar conceptos relativos a las clasificaciones y Modos Técnicos.

Otro aspecto tratado es la investigación traceológica, que pretende averiguar cuál es la utilidad de las herramientas. Para ello se estudian con ayuda de microscopios las modificaciones que en el pasado el uso de las herramientas produjo en los filos. Desde el punto de vista didáctico resulta muy interesante comprender cuáles son las técnicas de análisis que permiten al investigador alcanzar sus conclusiones.

\subsubsection{Los modos de vida}

Hay una serie de cuestiones acerca de los homínidos de Atapuerca que suelen plantear los asistentes a las conferencias o los propios visitantes de la exposición. Muchas están relacionadas con los 
modos de vida de estos homínidos. Si eran grupos organizados o no es algo que resulta complicado de establecer, aunque es verosímil pensar que probablemente el tamaño del territorio explotado por ellos variaba en función de la disponibilidad de los recursos como alimentos, zonas de refugio y materias primas. Cabe suponer, al menos para los homínidos del Pleistoceno medio, la existencia de un lenguaje articulado como herramienta para conseguir una importante cohesión de los grupos, en el seno de los cuales el período de aprendizaje durante la niñez podría ser largo.

Las condiciones de temperatura constante en las entradas de las cuevas hacen de éstas un lugar ideal para cobijar a estos grupos, sobre todo en momentos de rigor climático. En estas zonas abrigadas y protegidas del viento, como se ilustraba también en otra de las reconstrucciones científicas (Lám. III), los homínidos emplearían su tiempo en fabricar herramientas, descuartizar presas, curtir la piel o trabajar la madera para fabricar, por ejemplo, lanzas (3) (Márquez et alii, 1999).

La imagen tradicional sobre la dieta de los homínidos pleistocenos asumía un bajo consumo de alimentos vegetales. Sin embargo, hoy sabemos que los homínidos del Pleistoceno medio tenían una dieta variada, con un protagonismo importante de los recursos vegetales. Los recursos de este tipo, disponibles en el ecosistema en forma de frutos secos y carnosos, semillas, raíces, tubérculos y brotes tiernos de algunas plantas, constituían un nada desdeñable componente en su alimentación. Existe además otra ventaja, estos recursos son predecibles, para unos homínidos que en realidad son oportunistas, y ocupan a la vez los distintos nichos ecológicos de cazadores, recolectores y carroñeros (Bermúdez de Castro et alii, 1995). El hecho de considerar la dieta vegetal como especialmente importante viene avalado por el estudio de las microestrías de desgaste dentario y por la gran abrasión que presentan los dientes de algunos individuos, indicativos de la consumición de alimentos duros. Este esquema rompe con la idea popularizada del homínido gran cazador que se alimenta casi exclusivamente de carne.

El teatro virtual enlazaba con el intento de seguir conociendo más datos acerca de cómo se comportaba Homo antecessor. El teatro pretendía lle-

(3) Vergés, J.M. (1996): Impacte antropic i pautes tecnofuncionals al Plistocè Mitjà: la industria lítica del nivel TD10 de Gran Dolina (Sierra de Atapuerca, Burgos). Tesi de Llicenciatura, Universitat Rovira i Virgili, Tarragona. Inédita. gar a un amplio abanico de visitantes. Era una actividad de muy corta duración que el propio público podía poner en marcha, y que por los recursos luminosos y sonoros que utilizaba conseguía captar inmediatamente la atención de espectadores de casi cualquier edad. Consistía en una proyección de hologramas que nos permitían iniciar un viaje hacia atrás en el tiempo y contemplar, en su ambiente, a los protagonistas del pasado, a los Homo antecessor.

La mediateca ha sido visitada por los incondicionales de los ordenadores, interesados en Atapuerca y las curiosidades que rodean los descubrimientos. En la mediateca se ha tenido acceso a distintos elementos interactivos a través de ordenadores, en los que se ha podido consultar una hemeroteca sobre Atapuerca o conectarse a las páginas web que ofrecen amplia información sobre los subproyectos y las investigaciones desarrolladas. No faltaron los videojuegos, que hicieron las delicias de los más jóvenes cuando les permitía convertirse en excavadores virtuales de la Sima de los Huesos, arqueólogos y paleontólogos que con cierto aire de explorador de película se aventuraban en busca del cráneo perdido.

En la zona de receptores se podía escuchar también una emisión de radio acerca de la llegada a Europa de los primeros grupos humanos y los yacimientos de Atapuerca. Los codirectores de la excavación respondían a cuestiones de interés frecuente para el gran público.

\subsubsection{El diorama}

En un diorama a tamaño natural, como introducción al segundo ámbito, se representaron cuatro figuras reconstruyendo una escena de caza protagonizada por homínidos de la especie Homo heidelbergensis, y que pudo tener lugar hace 300000 años. Dichos individuos estaban descuartizando una cierva que acababan de abatir. Uno de ellos se encontraba reavivando un útil de piedra, mientras que otros dos despedazaban la pieza. El cuarto individuo transportaba una de las patas ya cortada.

Vuelve a ser patente la importancia concedida a los elementos tridimensionales, como herramienta importante para la transmisión de contenidos y la educación científica. Este diorama consiguió concentrar y proyectar al público, en menos de $10 \mathrm{~m}^{2}$, un gran contingente de información relacionada con el aspecto físico de los individuos que formaban 


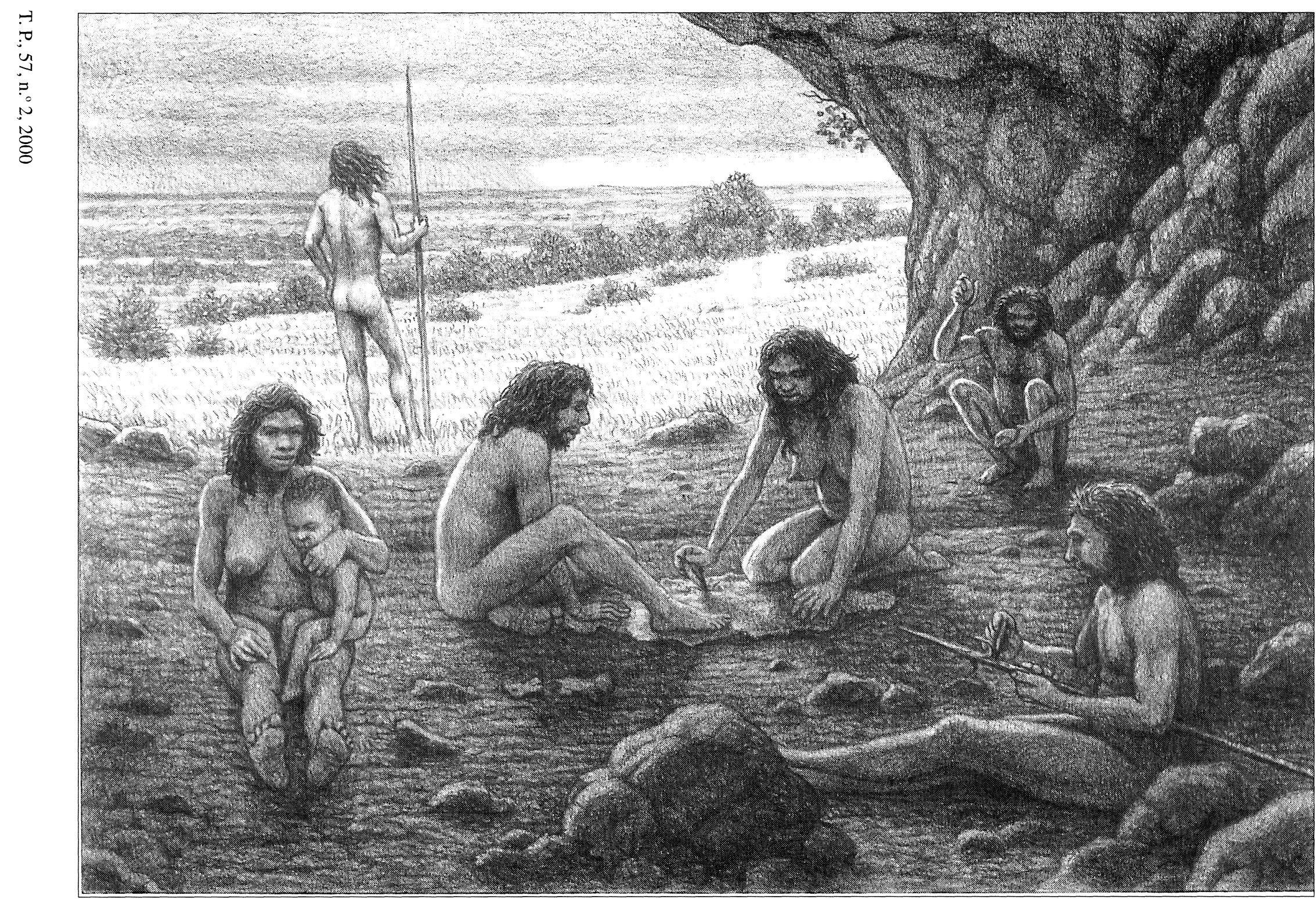

Lám. III. Grupo de homínidos refugiados en un abrigo. Exposición “Atapuerca: nuestros antecesores” (dibujo M. Antón). 
parte de los grupos humanos que van a evolucionar localmente en Europa durante el Pleistoceno Medio dando lugar a los grupos de Neandertales. Se podían observar las proporciones corporales y las diferencias anatómicas entre esta especie y la nuestra, así como algunos aspectos de su forma de vida, su cultura y la forma de obtener los recursos. La información llegaba a todos los públicos rápida y directamente, de forma visual e intuitiva.

\subsection{Segunda Parte: La Sima de los Huesos.} Homo heidelbergensis y los neandertales

1.3.1. La Sima de los huesos. Reconstruyendo la historia

Esta segunda parte de la exposición estaba presidida por la reproducción a escala 1: 1 de la Sima de los Huesos. En la Sima se han recuperado restos humanos de unos 32 individuos (Bermúdez de Castro y Nicolás, 1997) y de más de 160 osos de la especie Ursus deningeri, así como algunos leones (Panthera leo), linces (Lynx pardina spelaea), gatos monteses (Felis sylvestris), lobos (Canis lupus), zorros (Vulpes vulpes) y mustélidos (Martes sp.) (García et alii, 1997). Un par de vitrinas mostraban al visitante restos, a menudo espectaculares, de estos carnívoros. Un primer paso para el estudio de los restos es su identificación como elemento anatómico para después proceder a su identificación taxonómica. Un interactivo permitía al visitante probar por sí mismo la dificultad de esta labor. También se mostraba cómo, tras un paciente estudio, es posible recomponer un hueso a partir de múltiples fragmentos. Como caso espectacular se exhibió el molde de un cráneo en el que cada fragmento, a partir de los cuales se reconstruyó, aparecía pintado de un color diferente en función del año en que se encontró.

Las dos características más sobresalientes de la Sima de los Huesos son el excepcional estado de preservación de los restos y la abundancia de la muestra. La exhibición de dos de los huesos más pequeños del cuerpo humano recuperados en este yacimiento: el martillo y el yunque ilustraba el primero de los puntos, mientras que la abundancia de la muestra se representaba mediante la colección de astrágalos y mandíbulas, que también permitía apreciar la variabilidad de tamaño dentro de la población.

Una vez que hemos identificado el resto como humano cabe seguir indagando información sobre él. ¿Podemos inferir el sexo de los individuos? En algunos casos sí, como se ha mostrado en la vitrina que contenía una mandíbula femenina y otra masculina actuales al lado de dos mandíbulas de la Sima para las que se infiere distinto sexo.

La edad de muerte de un individuo puede estimarse a partir del estado de desarrollo y erupción de sus piezas dentarias y del grado de desgaste de las mismas, así como a partir del grado de fusión de las epífisis de los huesos largos. Sendos paneles explicaban mediante esquemas y radiografías este método. A partir de estos datos, un gráfico tridimensional mostraba las edades de muerte por sexos en la Sima de los Huesos.

\subsection{2. ¿Cómo murieron?}

Un estudio paleopatológico puede darnos pistas acerca de las enfermedades que sufrió en vida un determinado individuo, o incluso de las causas de su muerte. El cráneo 5, quizás la pieza más llamativa de toda la exposición, ya que se trata de uno de los cráneos más completos del Pleistoceno, presenta también una infección periodontal generalizada que probablemente acabó en una septicemia que le causó la muerte (Pérez et alii, 1997). La observación del cráneo original se complementaba con el texto explicativo de una vitrina cercana.

Una de las explicaciones más plausibles para interpretar la acumulación de los cadáveres en la Sima es que fueron depositados allí intencionadamente por sus compañeros de grupo (Arsuaga $e t$ alii, 1997). Esta idea del "primer entierro" se plasmó gráficamente en un cuadro que representaba a 4 homínidos transportando hacia una cueva, sobre una piel, el cadáver de un compañero, mientras al fondo observaban la escena algunos leones (Lám. IV). La presencia de estos félidos en el cuadro no es casual, ya que otros autores (Andrews y Fernández-Jalvo, 1997) han estudiado la superficie de los huesos humanos, y concluyen que han sido mordidos por un animal semejante. En este último caso, la primera acumulación de cadáveres se habría producido en otro lugar.

\subsubsection{Los neandertales}

Como colofón a esta parte de la exposición se dedicó un breve espacio a situar en un mapa interactivo los yacimientos europeos con restos de neandertales, especie descendiente de Homo heidelbergensis, a la que se asignaron los homínidos de la Sima de 


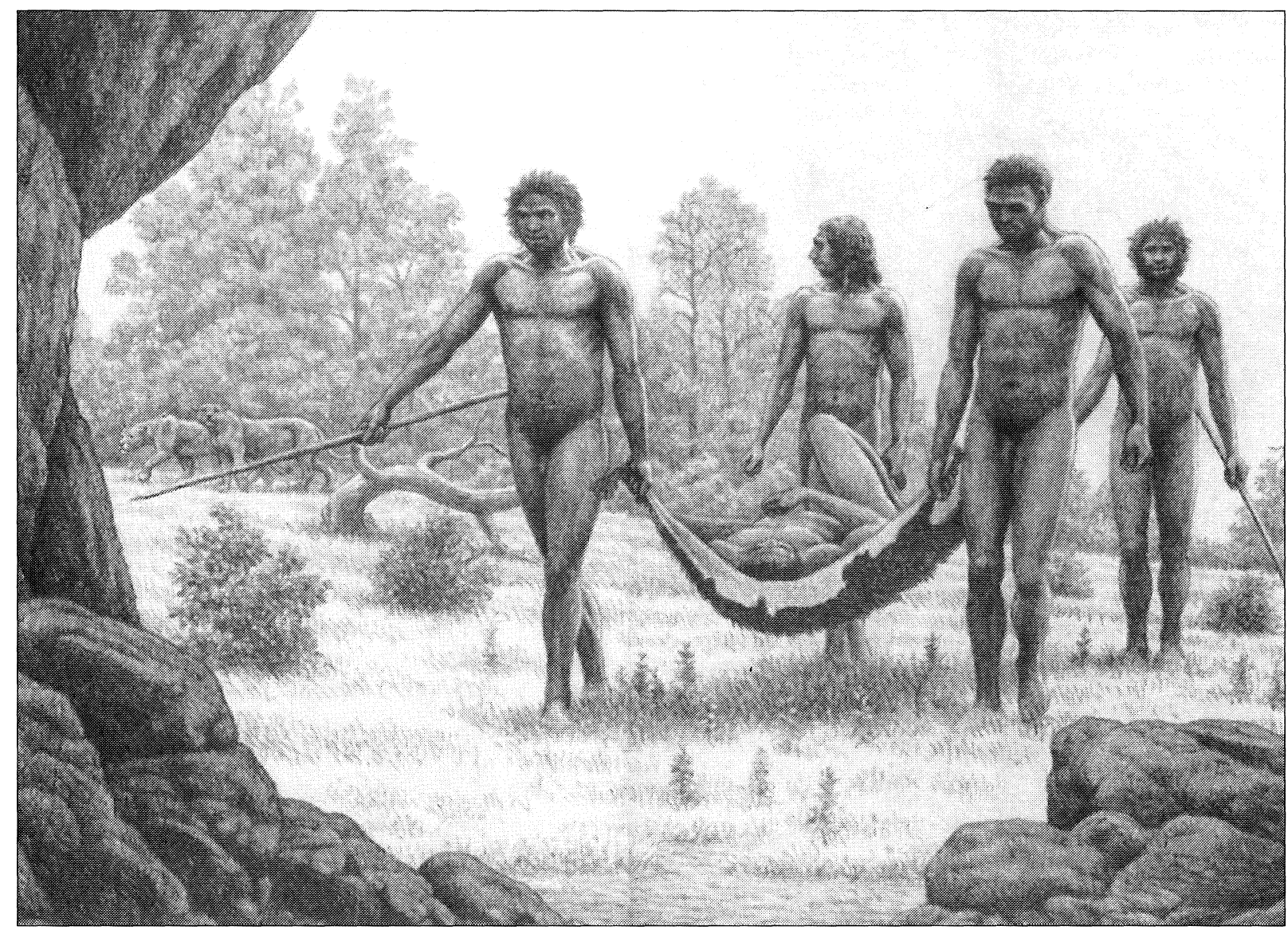

Lám. IV. Hipótesis de acumulación de los restos humanos en la Sima de los Huesos. Exposición “Atapuerca: nuestros antecesores" (dibujo M.Antón).

los Huesos. Se mostraban también algunas piezas de industria musterienses (Cueva Morín, Cantabria) y moldes de restos neandertales procedentes de otros yacimientos españoles (Valdegoba, Burgos).

\subsubsection{Esquema filogenético}

A esta altura el visitante ya tenía claro que la exposición deAtapuerca no ha sido una mera exhibición de fósiles y herramientas de piedra. El objetivo didáctico había ido adquiriendo progresivamente mayor intensidad. Así, el estudio concienzudo de los excepcionales hallazgos de los yacimientos deAtapuerca nos ha permitido conocer cómo dichos hallazgos han revolucionado nuestra forma de comprender la evolución humana (Lám.V).Y aún más, nos hemos acercado a la comprensión del motor de cambio evolutivo y podemos participar más eficazmente del nuevo paradigma.

\subsection{Tercera parte: ¿qué nos hizo humanos?}

Desde el principio, esta zona se planteó como un epílogo dedicado al visitante más interesado en profundizar en los procesos de la evolución humana. En lugar de seguir un discurso filogenético, como suele ser norma habitual, se propuso tratar por separado los diferentes aspectos del proceso de hominización (bipedismo, cerebro y parto, lenguaje, ciclo biológico e incremento progresivo de la complejidad). Para este fin se emplearon textos de una mayor extensión que los utilizados en las dos partes anteriores, acompañados de esquemas y réplicas de fósiles. Entre estas últimas se encontraban algunas tan espectaculares como los dos esqueletos humanos más completos del Plio-pleistoceno; "Lucy" (Australopithecus afarensis) y "El niño de Nariokotome" (Homo ergaster). 


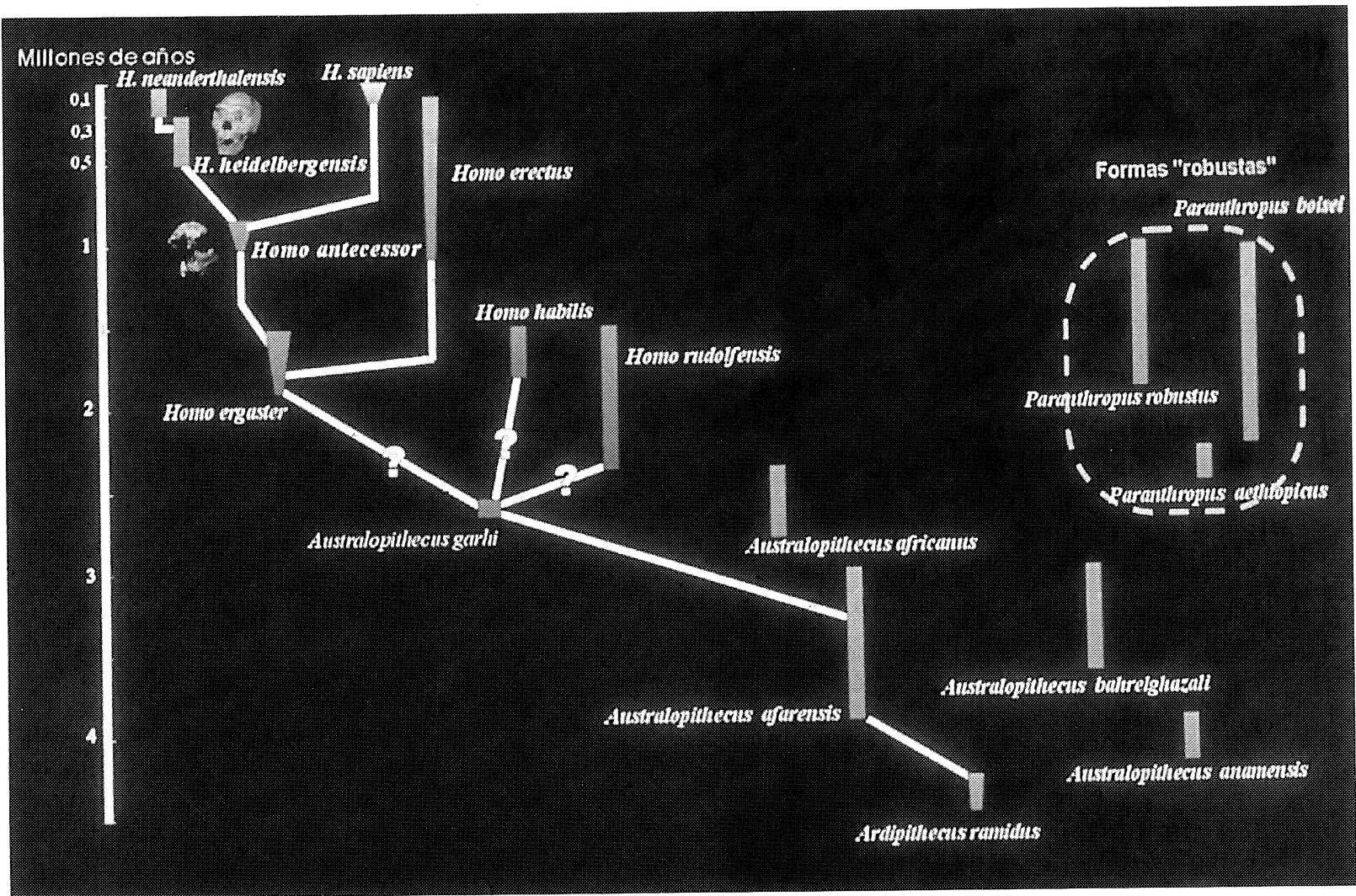

Lám. V. Filogenia de los homínidos según la propuesta del Equipo de Atapuerca.

\subsection{Interactivos no informáticos}

En las dos primeras partes se emplearon otro tipo de interactivos distintos a los puramente informáticos. El visitante pudo participar del propio método científico, experimentar y obtener conclusiones a partir de su propia observación.

En el primer interactivo se presentaban restos fósiles problema, los obtenidos por nosotros durante las excavaciones de los distintos yacimientos. La observación con fines puramente comparativos de distintas características del aparato masticador, como la forma de las coronas de los distintos dientes, la serie dentaria, el tamaño y la robustez de las mandíbulas permitían asignar cada uno de los fósiles problema a su Familia correspondiente (Cánidos, Suidos, Félidos, Bóvidos, Cérvidos, Mustélidos) identificada mediante un ejemplar representativo. El visitante experimentaba, improvisaba y participaba del ejercicio que realiza el paleontólogo durante la catalogación de los restos, y así comprendía el método científico.
El segundo interactivo estaba en el sector de la industria lítica. El público podía intentar responder a distintas cuestiones planteadas, relacionadas con las observaciones que acababa de realizar de los distintos modos técnicos industriales representados en los diferentes yacimientos de Atapuerca. Los visitantes podían aprender los conceptos resaltados, descubrir de forma participativa cuáles son las materias primas empleadas para fabricar las herramientas, a qué técnica de fabricación de herramientas asignarlas y el significado y la utilización de cada una de ellas.

Existía un tercer interactivo de este tipo, que permitía al visitante visualizar distintos restos desordenados y fragmentados pertenecientes a esqueletos de homínidos hallados en el yacimiento de la Sima de los Huesos, clasificados y ordenados en la zona esquelética correspondiente. El visitante imitaba al paleoantropólogo en el ejercicio de "reconstruir" los esqueletos de los homínidos acumulados en el fondo de la Sima de los Huesos a partir de las cada vez más numerosas piezas del puzzle antropológico. 


\section{LOS TALLERES DIDÁCTICOS DE LA EXPOSICIÓN}

Las exposiciones de los museos son, con mucha frecuencia, convencionales y están impregnadas de cierta estasis. Estas características modelan y tiñen el aprovechamiento que la mayoría de los sectores del público pueden realizar de ellas, lo que dificulta la consecución de los objetivos expositivos planteados.

El diseño expositivo debe contar con el apoyo de otros elementos coadyuvantes en el intento de transmitir conocimientos, y articular de distintas formas el aprendizaje de conceptos adecuándolo a los requerimientos de los diferentes segmentos educacionales. Así, pueden implementarse actividades paralelas y complementarias, caracterizadas por ser plenamente participativas y por ofrecer y aportar un componente novedoso a la hora de presentar contenidos.

El diseño de los distintos talleres paralelos a la exposición de Atapuerca fue el fruto de una estrecha colaboración entre especialistas en pedagogía del Departamento de didáctica del MNCN (Pilar López y Dolores Ramírez) y los autores (BM y EN), como integrantes del equipo investigador de Atapuerca. Los talleres constituían actividades complementarias a la visita a la exposición, con un componente educativo y participativo importante, estando destinados a público de diferentes edades. Dichos talleres, así como las visitas guiadas a la exposición, fueron realizados por monitores licenciados en Ciencias Biológicas, Geológicas y Prehistoria.

\section{1. ¡Comida, comida!...}

Esta actividad está recomendada para Educación Infantil y Primaria. La transmisión de conocimientos y la adquisición de conceptos para los grupos de educación infantil y primaria no tendría sentido si no se realizara de forma lúdica, siendo éste el fin perseguido por el taller.

Aquí se proponía a los más pequeños viajar en el tiempo con la imaginación para aterrizar en un paisaje de la Sierra de Atapuerca hace mucho, mucho tiempo... Se les caracterizaba con pieles y pelucas, y vestidos de "primitivos" y a lo largo de una hora se recreaban las actividades que realizaban los Homo heidelbergensis de hace 300.000 años, o los "abuelos de los neandertales", desde que comenzaba un día cualquiera de sus vidas hasta que decidían marcharse a descansar y dar por finalizada su jornada. Los niños aprendían los secretos de la obtención de comida y recursos en la sierra. Aprendían que el componente vegetal en la dieta de los homínidos era importante, así como también lo eran otros alimentos que podían encontrar en una jornada de recolección por la sierra o en las riberas del río Arlanzón.

El taller tenía un apartado de expresión plástica. Los niños comprendían el modo de fabricar herramientas de piedra e imitaban el producto final con pasta de modelar. Al finalizar, podían conservar las herramientas que fabricaron, pero antes, cazaban y carroñeaban dentro de las trampas naturales que constituyen las cuevas. Los niños retenían los detalles más inverosímiles relacionados con las actividades de los homínidos, y no les suponía dificultad alguna entender cómo se fabricaban herramientas, cómo los homínidos descuartizaban los animales para alimentarse, y por qué machacaban las diáfisis de los huesos largos. Se les había inculcado también cuáles son las ventajas de cuidar el medio y de compartir con el resto del grupo los alimentos obtenidos por unos pocos.

El componente lúdico e instructivo es fundamental para los grupos más jóvenes. Los disfraces y la dramatización como camino metodológico permiten adecuar los contenidos que se quieren transmitir y conseguir así que el aprovechamiento del taller sea satisfactorio.

\section{La excavación}

Con el fin de dar a conocer al público los detalles relativos al proceso de excavación, se construyó un "yacimiento" simulado en la zona dedicada a talleres. Estaba dirigido especialmente a personas mayores de 14 años, y su duración era de 1 hora.

Este yacimiento constaba de dos zonas distintas de 2,25 $\mathrm{m}^{2}$ de superficie cada una de ellas. Cada área estaba subdividida en cuadrículas de $50 \mathrm{~cm}$ de lado. Las dos representaban respectivamente parte de los niveles TG10 de Galería y TD6 de la Gran Dolina. Éstas se encontraban a distinto nivel la una de la otra con el fin de transmitir la idea de que existe efectivamente una diferencia cronológica entre las dos.

Los fósiles que se colocaron en cada una de las áreas eran réplicas exactas de los originales que se habían recuperado en los yacimientos y niveles arqueológicos reales. La distribución de los mismos no guardaba relación con la observada arqueológicamente. Sin embargo, la elección del fósil y su

T. P., 57, n. $^{\circ} 2,2000$ 


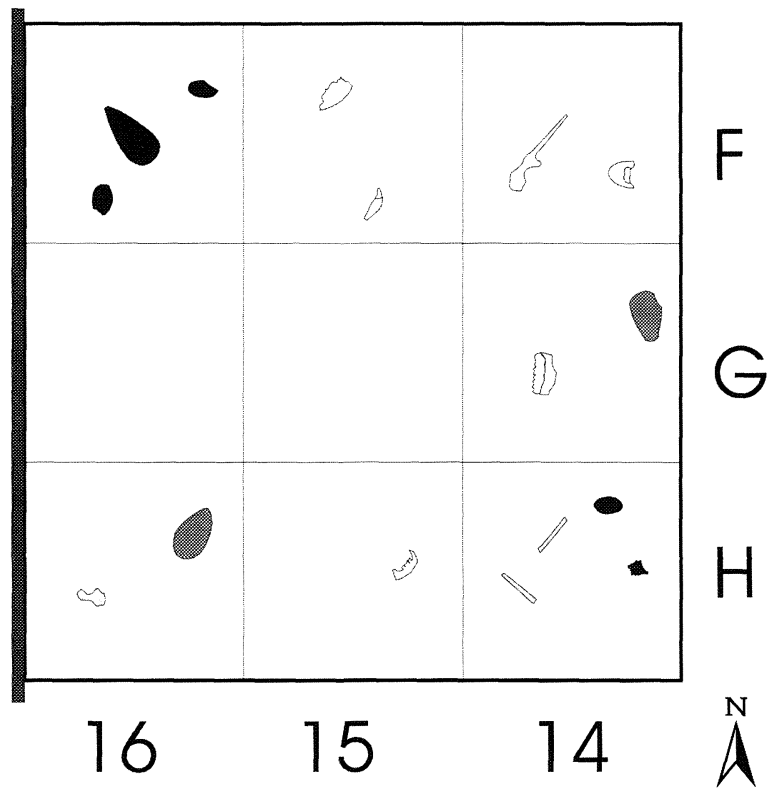

Fig. 5. Planta de la excavación simulada que representa el nivel TG10 deAtapuerca. Taller "La excavación" (exposición "Atapuerca: nuestros antecesores").

situación exacta en el yacimiento simulado obedecía a criterios didácticos (Fig. 5).

El sedimento elegido para tapar los restos fue sepiolita fina. Este producto no levanta polvo y puede ser fácilmente restituido a su lugar una vez finalizado el taller.

El material aportado al visitante consistía en útiles para excavar (recogedor, brocha y metro), así como una hoja de excavación por cuadrícula (Fig. 6). El monitor explicaba como debe abordarse dicha excavación para que pueda recogerse la máxima información posible. Una vez descubiertos los restos, el visitante los coordenaba con la ayuda del metro que se le proporcionaba y los describía en la hoja, tal como le explicaba el monitor. Así se podían rellenar todos los campos de la ficha salvo el que hacía referencia a la identificación del fósil. La complejidad que entraña la realización de la identificación anatómica y taxonómica de los fósiles se simplificaba mediante la colocación de tres grandes "panelesclave" en los que, dentro de las siluetas de cada especie de homínido o animal figura fotografiado cada fósil en su posición anatómica (Fig. 7). En el caso de la industria lítica se habían colocado siluetas que debían ser identificadas con el objeto recuperado.

Una vez reconocido el fósil, el excavador tomaba una serie de siluetas imantadas que se correspondían con cada una de las especies animales identi- ficadas, así como con la industria lítica y los homínidos. Éstas se pegaban respectivamente en uno de los dos grandes paneles que reproducían los posibles paisajes que vieron los homínidos que habitaron la sierra hace 300.000 años (Trinchera GaleríaTG10) y los que vivieron hace 800.000 años (Trinchera Dolina-TD6).

Las ideas que se ha pretendido fijar y que ha recogido el visitante durante y tras su visita son las siguientes:

- Utilización de técnicas arqueológicas como único método para poder reconstruir la vida en la Prehistoria. El incumplimiento de este protocolo llevaría a la pérdida parcial o total de información.

- El objeto y su contexto. El visitante, tras las explicaciones aportadas por el monitor, es consciente de que si se extrae un objeto del yacimiento pierde gran parte de su significado si no se pone en relación con el resto de los elementos que integran dicho yacimiento. Se intenta así que el público no especializado entienda el daño que ocasionan las excavaciones ilegales.

- Introducción a los estudios de Arqueología Espacial. Existe la posibilidad de distinguir áreas de actividad distintas en un mismo suelo de ocupación (p.e. taller de industria lítica, zonas de procesado de carcasas animales, etc.). La disposición elegida para las réplicas permitía explicar cómo se pueden reconocer estas áreas. Durante la explicación se introducían los conceptos de yacimiento in situ, y yacimiento en posición secundaria.

- Introducción a la Tafonomía. Se han elegido restos que muestran fracturas y marcas tanto de origen antrópico como de otros animales (p.e. marcas de roedor).

- ¿Cómo se determina la existencia de cambios en el medio ambiente? Éstos pueden ser detectados, entre otros, mediante el estudio de las asociaciones faunísticas conservadas en los yacimientos. El monitor explicaba cuáles son esas asociaciones a partir de los restos encontrados. Para poder simular la extracción de la información procedente de ítems poco evidentes durante la excavación simulada, como el análisis polínico o el de la microfauna, se enterraron en cada sector dos cajas de metacrilato que contenían respectivamente una fotografía de granos de polen y restos originales de microfauna. La explicación del monitor permitía al visitante conocer las condiciones y características reales de la extracción de dichas muestras. Por otra parte, se colocó una lupa binocular que permitía observar con 
YACIMIENTOS DE LA SIERRA DE ATAPUERCA (BURGOS)

HOJA DE EXCAVACIÓN. CAMPAÑa 1999

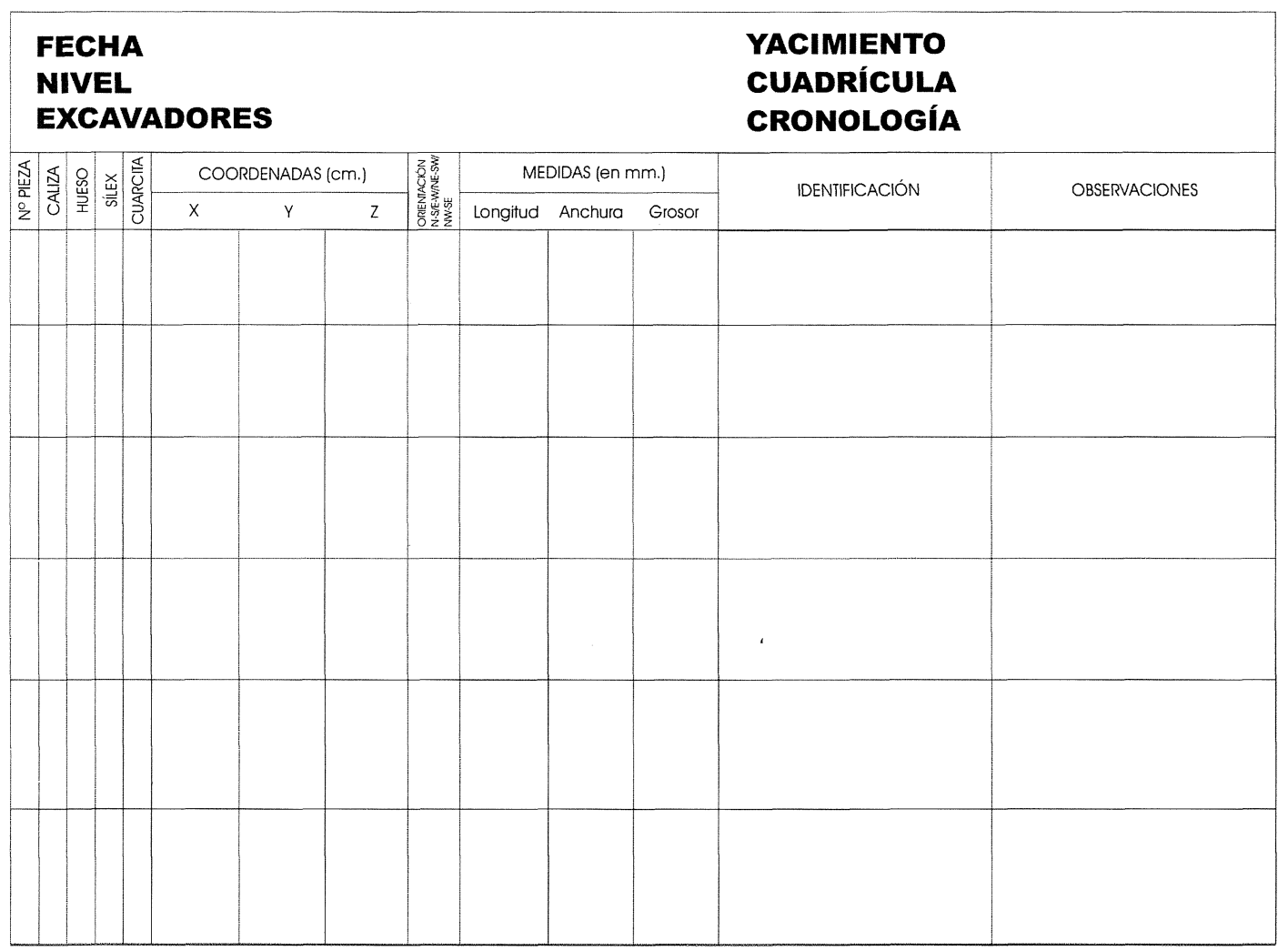

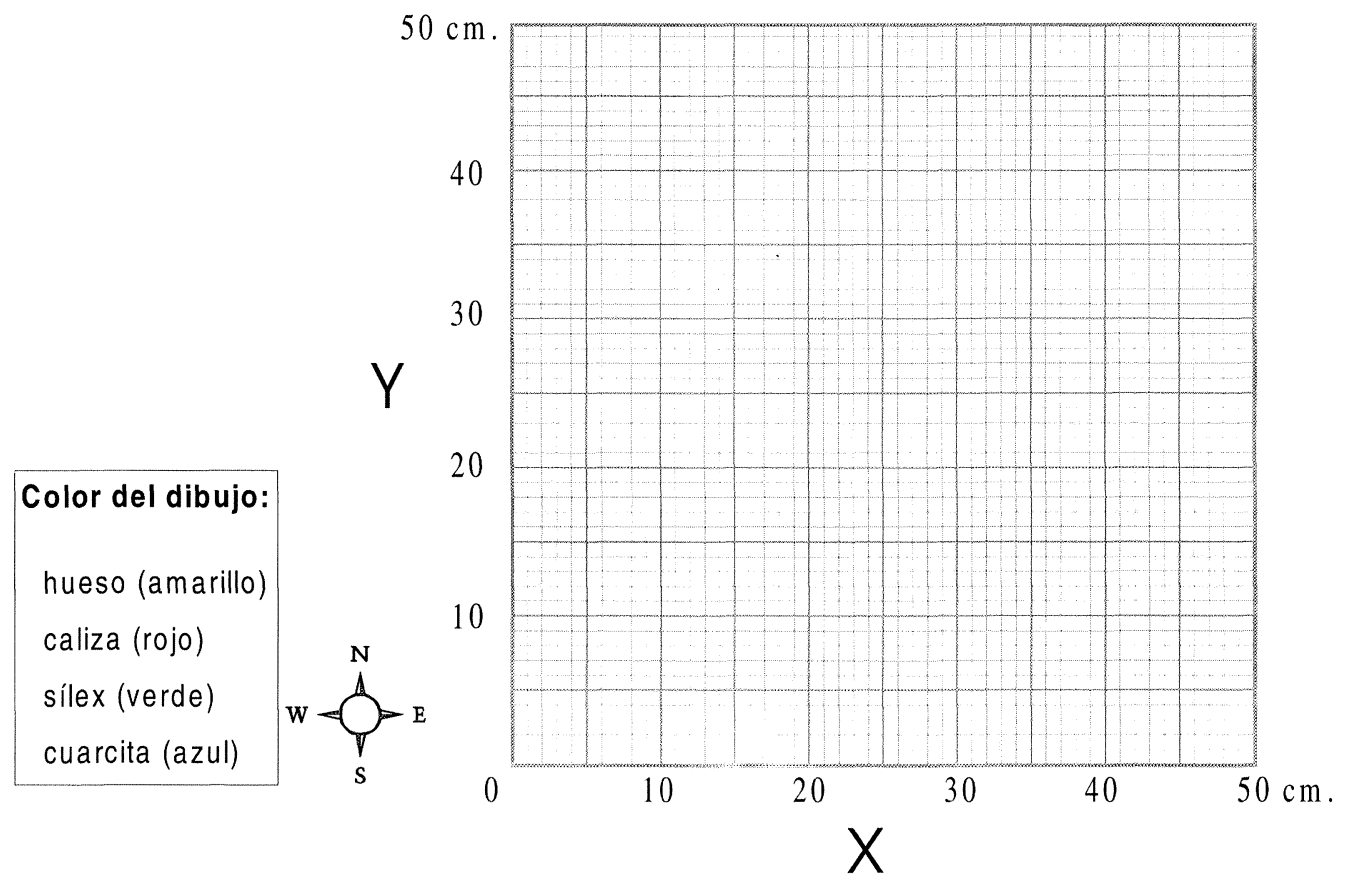

Fig. 6. Hoja de excavación del taller "La excavación”.

T. P., 57, n. ${ }^{\circ} 2,2000$ 


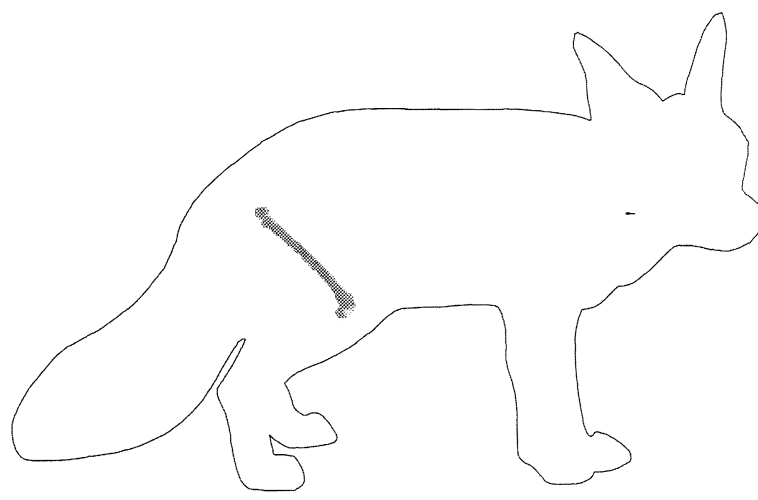

Fig. 7. Silueta de un zorro con la fotografía de un fémur en posición anatómica. Taller "La excavación" (exposición "Atapuerca: nuestros antecesores").

detalle las características de una muestra escogida de microfauna.

- ¿Cuál es la especie de homínido que pobló la Sierra hace 300.000 años? Se explicaba al visitante cómo, a pesar de que no se ha colocado ningún resto humano en el yacimiento simulado, sabemos que Galería fue visitada por homínidos.

- ¿Cómo eran y a qué especie pertenecían los homínidos que vivieron en la Sierra de Atapuerca hace 800.000 años? Gracias a que se contaba con moldes de muy alta resolución de los fósiles de Homo antecessor recuperados en el nivel 6 de la Gran Dolina se podía explicar al visitante, desde el punto de vista anatómico, cuáles son las características que hacen de este homínido una especie nueva.

- ¿De qué murieron y a qué edad? La resolución de los moldes permitía al excavador observar sobre los fósiles humanos las marcas de corte que han permitido conocer las prácticas de canibalismo más antiguas en la historia de la humanidad conocidas hasta la fecha. El hecho de que se conserven varios fragmentos de mandíbula y maxilares ha permitido estimar, a partir del estudio del desgaste y del momento de erupción de las piezas dentarias, la edad de muerte de estos individuos.

El visitante, tras la participación en el taller, contaba con una idea del trabajo arqueológico y de reconstrucción de las economías prehistóricas mucho más completa.

\section{3. "El hilo del tiempo" y "Sigue los pasos"}

"El Hilo del tiempo" pretendió transmitir la idea de Tiempo Geológico, un concepto difícil de aprehender en sí mismo. Mediante este taller se situa- ba cronológicamente la aparición y desaparición de las especies de homínidos más representativas y se daba una idea de sus características físicas gracias a la utilización de siluetas de madera con la fotografía de un fósil de cada especie a escala natural, que el visitante debía colocar en orden cronológico siguiendo las pistas que se le proporcionaban. El monitor formulaba una serie de preguntas que podían ser contestadas observando la posición de cada silueta en el "Hilo del Tiempo", y explicaba de forma sucinta la filogenia humana, que es mucho más compleja que la idea que surge de la mera contemplación de las siluetas en el "Hilo". Con todo ello se podían fijar los conceptos aprendidos.

En el taller "Sigue los Pasos" los estudiantes barajaban y conocían las distintas hipótesis posibles para dilucidar cómo se produjo el primer poblamiento del continente europeo. Con ayuda de un mapa político, sobre un gran mapa mudo se reconstruyeron las posibles rutas migratorias que desde hace aproximadamente un millón de años, pudieron seguir los primeros homínidos que salen de África con destino a Europa (Fig. 8). Es lógico pensar que ha habido pulsos de oleadas migratorias, de distinta intensidad y en distintos momentos, que pudieron llegar a ser muy numerosos. Resulta también chocante comprobar que a pesar de ser el trazado más corto, ninguna de las rutas migratorias pasaba por el estrecho de Gibraltar.

El objetivo de estos dos talleres fue transmitir los siguientes conceptos:

- Diversidad de homínidos. Se presentaron las diferentes especies que existieron en el pasado y se dió una idea de sus proporciones corporales, y los rasgos físicos más relevantes.

- Conocer los distintos pulsos migratorios. Se mostraban las posibles rutas de dispersión de los australopitecos, Homo erectus, H. antecessor y $H$. sapiens, y los momentos en que se produjeron. Se destacaba también la dificultad de paso por el Estrecho durante el Pleistoceno.

- Importancia de los estudios moleculares. El estudio delADN permite conocer la realidad de las últimas oleadas migratorias, que debieron producirse hace unos 150.000 años y que fueron el inicio del poblamiento tardío de todos los continentes.

\section{Taller de talla lítica}

Con el fin de mostrar de forma práctica la evolución tecnológica al gran público se planteó un 


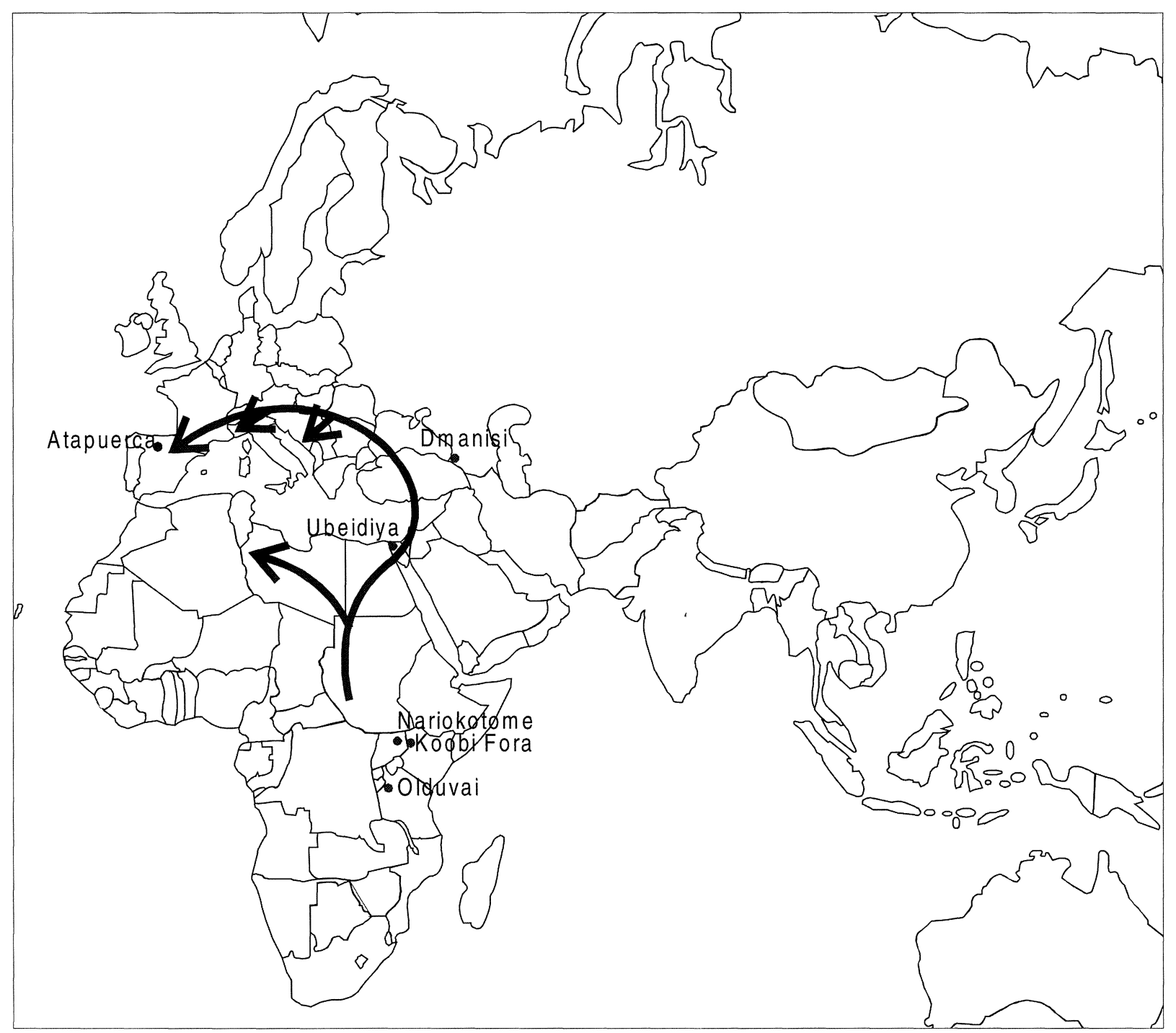

Fig. 8. Posible ruta migratoria de Homo antecessor. Taller "Sigue los Pasos" (exposición “Atapuerca: nuestros antecesores").

taller en el que un especialista realizaba una demostración de talla, durante la cual se explicaba el proceso de fabricación de herramientas, así como el porqué de la evolución de las técnicas de talla en el tiempo.

\section{CONCLUSIONES}

La exposición "Atapuerca: nuestros antecesores" ha servido para acercar al gran público los resultados de 20 años de investigaciones, desarrolladas por un equipo multidisciplinar en la Sierra deAtapuerca (Burgos). A lo largo del año que ha durado la exposición (del 17 de Mayo de 1999 al 31 de Mayo de
2000) se ha podido constatar el interés que despiertan en el público en general la evolución humana y la Prehistoria cuando los contenidos se transmiten de una forma amena y asequible. El esfuerzo conjunto de todo el Equipo de Investigación, en estrecha colaboración con los especialistas en didáctica y museología y todo el personal del Servicio de Fotografía y del Departamento de Exposiciones y Programas Públicos del Museo Nacional Ciencias Naturales, hizo posible la creación de un proyecto expositivo riguroso y, a la vez, didáctico y ameno.

La acogida recibida por parte del público, que ha superado todas las expectativas, supone un acicate para todo el equipo de investigación, y para la investigación arqueológica y paleontológica en general, 
tanto en lo que se refiere a la continuación de los trabajos como al desarrollo de nuevos proyectos de divulgación. La exposición ha sido también un magnífico escaparate para los pueblos de la zona donde se encuentran los yacimientos, atrayendo hacia ellos un turismo cultural compatible con el desarrollo sostenible de la región.

\section{AGRADECIMIENTOS}

Los autores quieren agradecer su esfuerzo e ilusión a todas aquellas personas que han participado en el diseño y montaje de la exposición y talleres. A la dirección del Museo Nacional de Ciencias Naturales por acoger e impulsar el proyecto de exposición. A los monitores de los talleres y visitas guiadas por su dedicación y empeño en hacer llegar al público de la manera más didáctica posible los resultados de 20 años de trabajo en Atapuerca. Así mismo, queremos agradecer a Mauricio Antón que nos haya permitido reproducir sus dibujos.

\section{BIBLIOGRAFÍA}

Andrews, P. y FernándeZ-Jalvo, Y. (1997): "Surface modifications of the Sima de los Huesos fossil humans". Journal of Human Evolution, 33: 191-217.

Arsuaga, J.L. (1999): El Collar del Neandertal. Temas de hoy. Madrid.

Arsuaga, J.L.; Bermúdez de Castro, J.M. y Carbonell, E. (eds.) (1997): "The Sima de los Huesos hominid site". Special issue of Journal of Human Evolution, 33 (2/3) (August/September).

Arsuaga, J.L. y MARTíneZ, I. (1998): La especie elegida. La larga marcha de la evolución humana. Temas de Hoy. Madrid.

Bermúdez de Castro, J.M.; Díez, J.C.; Mosquera, M.; Nicolás, M.E.; Rodríguez, J.; Sánchez, A. y PérezPÉreZ, A. (1995): El nicho ecológico de los homínidos de Atapuerca". Complutum, 6: 9-56.

Bermúdez de Castro, J.M.; Arsuaga, J. L.; Carbonell, E.; Rosas, A.; Martínez, I. y Mosquera, M. (1997): “A hominid from the Lower Pleistocene of Atapuerca, Spain: Possible ancestor to Neandertals and modern humans". Science, 276: 1392-1395.

Bermúdez de Castro, J.M.; Arsuaga, J.L.; Carbonell, C. y Rodríguez, J. (eds.) (1999): Catálogo de la Exposición "Atapuerca, nuestros antecesores". Junta de Castilla y León. Valladolid.

Bermúdez de Castro, J.M. y Nicolás, M.E. (1997): “Pa- laeodemography of the Atapuerca-SH Middle Pleistocene hominid sample". Journal of Human Evolution, 33: 333-355.

Bischoff, J.L.; FitzPatrick, J.A.; León, L.; ARsuaga, J.L.; Falgueres, C.; Bahain, J.J. y Bullen, T. (1997): "Geology and preliminary dating of the hominid-bearing sedimentary fill of the Sima de los Huesos Chamber, Cueva Mayor of the Sierra de Atapuerca, Burgos, Spain". Journal of Human Evolution, 33: 129-154.

Carbonell, E.; Bermúdez de Castro, J.M.; Arsuaga, J.L.; Díez, J.C.; Rosas, A.; Cuenca-Bescós, G.; Sala, R.; Mosquera, M. y Rodríguez, X.P. (1995): "Lower Pleistocene hominids and artefacts from AtapuercaTD6 (Spain)". Science, 269: 826-830.

Carbonell, E. y SAla, R. (2000): Planeta humà. Ed. Empúries. Barcelona.

Cervera, J.; Arsuaga, J.L.; Bermúdez de Castro, J.M. y Carbonell, E. (1998): Atapuerca. Un millón de años de historia. Ed. Complutense. Madrid.

Comité de RedACCIón (1997): "Premio Príncipe deAsturias de Investigación al equipo deAtapuerca". Trabajos de Prehistoria, 54 (1): 9-15.

García, N.; Arsuaga, J.L. y Torres, T. (1997): “The carnivore remains from the Sima de los Huesos Middle Pleistocene site (Sierra de Atapuerca, Spain)". Journal of Human Evolution, 33: 155-174.

Márquez, B.; Ollé, A. y SAla, R. (1999): -Análisis microscópico de los instrumentos de Galería (Sierra de Atapuerca). Actividades desarrolladas y formas de uso". En E. Carbonell, A. Rosas y J.C. Díez (eds.): Atapuerca: Ocupaciones humanas y paleoecología del yacimiento de Galería. Monografías Arqueológicas, 7. Junta de Castilla y León. Valladolid: 353-369

Parés, J.M. y Pérez-González, A. (1995): “Paleomagnetic age for hominid fossils at Atapuerca archaeological site, Spain". Science, 269: 830-832.

Pérez, P.J.; Gracia, A.; Martínez, I. y Arsuaga, J.L. (1997): "Paleopathological evidence of the cranial remains from the Sima de los Huesos Middle Pleistocene site (Sierra deAtapuerca, Spain). Description and preliminary inferences". Journal of Human Evolution, 33: 409-421.

Rosas, A.; Carbonell, E.; Ollé, A.; Pérez González, A.; Vall Verdú, J.; Huguet, R.; CÁceres, I.; Rosell, J.; SAla, R.; Mosquera, M.; VAN der MAde, J.; SÁNChez, A.; Cuenca, G.; Rodríguez, X.P. y Rodríguez, J. (1999): "Contribución del yacimiento de Galería (Sierra de Atapuerca) al Cuaternario Ibérico”. En E. Carbonell, A. Rosas y J.C. Díez (eds.): Atapuerca: Ocupaciones humanas y paleoecología del yacimiento de Galería. Monografías Arqueológicas, 7. Junta de Castilla y León: 377-390.

ZAZO, C.; GoY, J.L. y Hoyos, M. (1983): "Estudios geomorfológicos de los alrededores de la Sierra de Atapuerca (Burgos)". Estudios Geológicos, 39: 179-185. 